\title{
Structural Deformation of a Ring-shaped Re(I) Diimine Dinuclear Complex in the Excited State
}

Sei'ichi Tanaka ${ }^{1}$, Yoshitaka Matsubara ${ }^{1}$, Tsuyoshi Asatani ${ }^{1}$, Tatsuki Morimoto², Osamu Ishitani ${ }^{1}, K$ Ken Onda ${ }^{3,4}$, *

1Department of Chemistry, School of Science, Tokyo Institute of Technology, O-okayama, Meguro-ku, Tokyo 152-8551, Japan

2Department of Applied Chemistry, School of Engineering, Tokyo University of Technology, Katakura, Hachioji, Tokyo 192-0982, Japan

${ }^{3}$ Interactive Research Center of Science, Tokyo Institute of Technology, Nagatsuta, Midori-ku, Yokohama, Kanagawa 226-8502, Japan

4JST,PRESTO, 4-1-8 Honcho, Kawaguchi, Saitama 332-0012, Japan

${ }^{*}$ Corresponding author

E-mail: onda.k.aa@m.titech.ac.jp

\begin{abstract}
We investigated the excited state of a ring-shapeddinuclear $\operatorname{Re}(\mathrm{I})$ diimine bis-carbonyl complex that shows promise with regard to efficient photosensitized reactions and multi-electron storage, using time-resolved infrared(TR-IR) vibrational spectroscopy and quantum chemical calculations. Anomalouspeaks in the $\mathrm{CO}$ stretching region of the TR-IR spectrum werewell reproduced by the calculations. It was found that metal-to-ligand charge transfer occurs only in one of the Re complex units, andthat the excited state geometry is deformed relative to the ground state in order to relax the associatedsteric tension.Thisstructural deformationgenerates the unique photophysical properties of the complex.
\end{abstract}

C 2016 . This manuscript version is made available under the Elsevier user license

http://www.elsevier.com/open-access/userlicense/1.0/ 
1. Introduction

Assembling photofunctional molecules into ring structuresis one means ofimprovingtheirperformance, although only a few examples have been reported thus far. The best-knowncompoundsof this type arethe ring-shaped chlorophyll compounds employed during photosynthesis by purple bacteria [1], along with the ring-shapedporphyrin oligomers [2,3].However, compared to these compounds, ring-shaped $\operatorname{Re}(\mathrm{I})$ diimine complexes have many advantages [4-6], since mono-nuclear Re(I) diimine complexes absorb and emit visible light efficiently [7,8] and their excited statesexhibitlong lifetimes andcan function as photo-redox agents or photocatalysts[9-16].Subsequent to forming a ring-shape, these complexesare more efficient redox photosensitizers [4] and canstorea greater quantity ofelectrons [5]. In addition, it is easy to control the size of these ring structures andto generate hetero-membered rings.

Thephotophysical propertiesof such systems, including absorption wavelength, emission wavelength and phosphorescence lifetime, have already been systematically investigated $[4,6]$. It has been determined that these properties depend greatly on the size of the ring, since decreasing the size of theinternal ring cavitycan significantly affect the photophysical properties of the rings themselves. In particular, the dinuclear ring $\left(\mathrm{R}^{2} \mathrm{~b}^{2+}\right)$ shown in Fig. 1exhibits an emission quantum yield $(\Phi e m=0.081) 4.5$ times greater and anemission wavelength $\left(\lambda_{\mathrm{em}}{ }^{\max }=611 \mathrm{~nm}\right) 24 \mathrm{~nm}$ shorter than those of the corresponding mononuclear $\operatorname{Re}(\mathrm{I})$ complex $\left(\mathrm{M}^{+}:\right.$Фem $=0.018$ and $\left.\lambda_{\mathrm{em}}{ }^{\max }=635 \mathrm{~nm}\right)$, eventhough the absorption maxima of both complexes are very $\operatorname{similar}\left(\mathbf{R} 2 \mathbf{b}^{2+:} \lambda_{\mathrm{abs}}{ }^{\max }=\right.$ $415 \mathrm{~nm}, \mathbf{M}^{+}: \lambda_{\text {abs }}{ }^{\max }=414 \mathrm{~nm}$ )[4]. In order to elucidate the manner in whichthe characteristic propertiesof this compound are affectedby forming a ring, the present work explored the electronic and molecular structures of a ring-shaped Re(I) dinuclear complex in the excited state, using a combination of time-resolved infrared spectroscopy (TR-IR) and quantum chemical calculations.

TR-IR is one of the most useful methods of studying the excited state characteristics of transition metal complexes. TheCO ligands of metal complexes are an especiallygood probe for the investigation of electronic and molecular structures in the excited state, owing to the $d \pi^{-} \pi^{*}$ back donation between the central metal and these ligands[17]. In the case of the $\operatorname{Re}(\mathrm{I})$ diimine carbonyl complexes, many excited state characteristics have been clarified by observing the vibrations of CO ligandsby TR-IR [16-33].Quantum chemical calculations, using a program packagesuch as Gaussian,are another important tool for the study of transition complexes in the excited state. Although the results of such calculations for the excited states of organic compounds are not especially reliable, 
it has recently been shown thatthe resultsobtained for thelowest triplet state $\left(\mathrm{T}_{1}\right)$ are in good agreement with the TR-IR spectragenerated bythe meta-stable triplet statesof transition metal complexes [22, 25, 26, 28, 34-36]. Considering that the energies and intensities of sharp vibrational bands are very sensitive to electronic and molecular structures, the reliability of the quantum calculations issufficiently highso as to allow a discussion of the properties of such metal complexes in the excited state.

\section{Experimental}

\subsection{Acquisition of TR-IR spectra}

TR-IR spectra were obtained via the pump-probe method using a femtosecond Ti:sapphire chirped pulse amplifier (CPA, wavelength: $800 \mathrm{~nm}$, pulse duration: $120 \mathrm{fs}$, repetition rate: $1 \mathrm{kHz}$ ). The details of the procedure have been previously reported [34-36].A tunable mid-infrared pulse $\left(1000-4000 \mathrm{~cm}^{-1}\right)$ was obtained by difference frequency generation (DFG) between the signal and idler beams of an optical parametric amplifier (OPA) pumped by a part of the output of the CPA. The ultraviolet pump pulse (400 $\mathrm{nm}$ ) was obtained by second harmonic generation (SHG) of the other part of the output of the CPA. The pump and probe pulses were focused on an infrared flow cell equipped with $\mathrm{BaF}_{2}$ windows (optical path length: $0.1 \mathrm{~mm}$ ). The fluence of the pump pulse was approximately $10 \mathrm{~mJ} / \mathrm{cm}^{2}$. The probe pulse passed through the flow cell and was subsequently dispersed by a $19 \mathrm{~cm}$ polychromator and detected with a 64channel lineararray IR detector.

The sample complexes were synthesized following a previously reported procedure [4]. Following the preparation of $1 \mathrm{mM}$ acetonitrile solutionsof each complex using this procedure, the air dissolved in the solutions was purged by sparging with Ar gasfor more than one hour.

\subsection{Quantum chemical calculations}

The quantum chemical calculations were performed withthe Gaussian 09 program [37]. The optimized structures were obtained using the mPW1PW91 functional and the LanL2DZ basis set with polarization functions. The calculatedlowest singlet $\left(\mathrm{S}_{0}\right)$ and lowest triplet $\left(\mathrm{T}_{1}\right)$ states correspond to the observed ground and excited states, respectively. The IR spectra of the $\mathrm{S}_{0}$ and $\mathrm{T}_{1}$ states were obtained from the optimized geometries with a scaling factor of 1.005. Time-dependent density functional theory (TD-DFT) calculations were also performed to allow study of the vertical excitation from the $\mathrm{S}_{0}$ to $\mathrm{S}_{1}$ states. 
3. Results and discussion

The target ring-shaped complexR2 $\mathrm{b}^{2+}$ contains two $\operatorname{Re}(\mathrm{I})(\mathrm{bpy})(\mathrm{CO})_{2}\left(\mathrm{PPh}_{2}\right)_{2}$ units connected to one another via two $\mathrm{Ph}_{2} \mathrm{P}\left(\mathrm{CH}_{2}\right)_{4} \mathrm{PPh}_{2}$ bridge ligands. The detailed structure of this complex, as determined by X-ray diffraction,has been reported in Ref. [4]. Figure 2(a)shows the TR-IR spectraacquired $800 \mathrm{ps}$ after photoexcitation, over the range of $1825-2050 \mathrm{~cm}^{-1}$ in which the $\mathrm{CO}$ stretching vibrations are located.Three transient absorption bands are evident at 1860, 1900 and $1994 \mathrm{~cm}^{-1}$ as well as two bleach bands at 1876 and $1932 \mathrm{~cm}^{-1}$.At this delay time, the complex has already relaxed to the bottom of the lowest triplet state; thus, these transient absorption bands are assigned to vibrational transitionsfrom the vibrational ground state of the triplet excited state. In contrast, the bleach bands are attributed to thereduction of IR absorption in the ground state.

The IRabsorption spectra of the CO stretching vibrations of mononuclear Re(I) diimine bis-carbonyl complexeswith acis, trans-[Re(diimine $\left.)(\mathrm{CO})_{2}\left(\mathrm{PR}_{3}\right)\right]^{+}$structure havebeen comprehensively investigated [38] and the TR-IR spectra of some mononuclear Re(I) diimine bis-carbonyl complexes have also been studied [17, 18]. According to these reports, the higher and lower wavenumber bands are generally assigned to the symmetric and anti-symmetric vibrations of the two $\mathrm{CO}$ bonds, respectively. As an example, we show the TR-IR spectrum of $\mathbf{M}^{+}$obtained by the same procedure as employed for the R2 $\mathbf{b}^{2+}$ complex in Fig. 2(b). Upon photoexcitation with $<500 \mathrm{~nm}$ light, the meta-stabletriplet metal-to-ligand charge transfer state (3MLCT) is generated,in which the excited electron is localized on the diimine ligand. As a result of this charge transfer, the CO stretching bands in the TR-IR spectrumexhibit a significant blue shiftof $35-60 \mathrm{~cm}^{-1}$. This occurs because there is an electron-pair donation from thed $\pi$ orbital of the central metal to the $\pi^{*}$ orbitals of the CO ligands (representing $d \pi^{-} \pi^{*}$ back donation) in the ground state. The associated reduction of the negative charge on the central metal by photoexcitation weakens this effect and strengthens the bonds inside the CO ligands. Table I summarizes the wavenumbers ofthe CO stretching vibrational modes of themononuclear Re(I) diimine bis-carbonyl complexes and of $\mathrm{R}^{2} \mathrm{~b}^{2+}$.

In the TR-IR spectrum of $\mathrm{R}^{2} \mathrm{~b}^{2+}$, the bands at 1900 and $1994 \mathrm{~cm}^{-1}$ can be assigned to the vibrational modesassociated with the MLCT excitation of one of the two Re complexunits. However, the band at $1860 \mathrm{~cm}^{-1}$ cannot be explained by this simple theory, indicating that some other process occurs only in the excited state of the ring dinuclear complex. In order to investigate this spectral anomaly, we carried out quantum chemical calculations. Figs. 2(c) and (d) show the calculated difference spectrum between the $\mathrm{T}_{1}$ and $\mathrm{S}_{0}$ states and the calculated spectra forthe $\mathrm{T}_{1}$ (red line) and $\mathrm{S}_{0}$ (blue line) states, 
respectively. The calculated difference spectrum well reproduces the characteristics of the TR-IR spectral pattern, including the anomalous $1860^{-\mathrm{cm}^{-1}}$ band.According to Fig. $2(d)$, this characteristic spectral pattern results from thefour vibrational bands of the $T_{1}$ state.This result indicates that the symmetry of the excited state is different from that of the ground state. It is worth noting that the anomalous positive scaling factor of 1.005 is presumably caused by the residual steric tension induced upon forming the ring, as discussed further on.

The arrows in Fig.3indicatethe vibrational phasing between the $\mathrm{CO}$ stretching vibrations as estimated from the calculated normal vibrational modes. In the $\mathrm{S}_{0}$ state, the observed bands at 1876 and $1932 \mathrm{~cm}^{-1}$ are assigned to the anti-symmetric and symmetric vibrationsof both Re complex units, respectively. In contrast, in the case of the $\mathrm{T}_{1}$ state, the wavenumbers of the bands differ between the Re complex units: the bands at 1860 and $1994 \mathrm{~cm}^{-1}$ (indicated by the blue circle in Fig. 2a) are assigned to the anti-symmetric and symmetric vibrationsof one Re complex unit (blue arrows on the right side), respectively, whereas the bands at 1932 and $1900 \mathrm{~cm}^{-1}$ (indicated by the red circle in Fig. 2a) are assigned to the anti-symmetric and symmetric vibrations of the other (red arrows on the left side). Thus, it is concluded that this loss of symmetrybetween the two Re complex units causes the anomalous vibrational pattern in the TR-IR spectrum.

The electroniccharacteristics ofthe ground and excited stateswere estimated from the frontier molecular orbitals of the $\mathrm{S}_{0}$ and $\mathrm{T}_{1}$ states obtained from calculations. Fig. 4 shows the highest occupied molecular orbitals (HOMOs) of the $\mathrm{S}_{0}$ state and the lower and highersingly occupied molecular orbitals (SOMO1 and SOMO2) of the $\mathrm{T}_{1}$ state. Because of symmetry, the HOMOs in the $\mathrm{S}_{0}$ state are degenerate, whereas this degeneracy is resolved due to the loss of symmetry in the $\mathrm{T}_{1}$ state, as shown in the upper panel in Fig. 4. We note that the total charge of each Re complex unit is neutral in both the $\mathrm{S}_{0}$ and $\mathrm{T}_{1}$ states; thus, no charge transfer occurs between the two Re complex units.In the $\mathrm{S}_{0}$ state, the HOMOsareevenly delocalized on both Re atoms. In the $\mathrm{T}_{1}$ state, the SOMO1 is stilllocalized on the Re atom but only on one Re complex unit (the right side), and the orbital distribution is verysimilar to that of the HOMO on one side of the Re complex in the $\mathrm{S}_{0}$ state. Considering that the difference in the frontier orbitalsdetermines the variation in charge distribution between the two states, there is almost no change in charge distribution on the right side Re complex unit.Conversely, the SOMO2 is localized on the bpy ligandon the other Re complex unit (the left side). This difference in the frontier molecular orbitals indicates that the MLCT from the Re atom to the bpy ligandoccurs on the left side Re complex unit. These molecular orbitals 
are only minimally distributed to sites other than the Re, CO and bpy, such as the phenyl groups and alkyl bridges. Thus, it can be said that all the structural deformation in the excited state originates from this MLCT on the one Re complex unit.

At this point, we discuss the details of the structural changeson going from the ground to excited state on the basis of the calculated optimized geometries shown in Fig. 5. Fig. 6 summarizes the differences in the bond lengths and angles in the geometries of the $\mathrm{S}_{0}$ and $\mathrm{T}_{1}$ states. The most noticeable difference is that theplane defined bythe two COligands andRe atom of the right side Re complex unit is tilted by $7^{\circ}$ relative to that of the left side Re complex unit, as can be seen in Fig. 5.Strictly speaking, the planesare slightly deviated from the Re-Re axis.Another remarkable feature is that the P-Re-P angle of the left side Re complex unit (P2-Re1-P5) is decreased by $5^{\circ}$. In addition, some anglesand bond lengths of both the left and right side Re complex unitsareslightly changed, $\sim 1^{\circ}$ or $\sim 0.01 \AA$.

Based on these results, we propose a mechanism for the structural deformations in the excited state. In this mechanism, the MLCT induced by photoexcitation reduces the negative charge of the Re atom in one Re complex unit (the left side in this case) and reduces the $\mathrm{d} \pi-\pi *$ back donationassociated with both the Re-CO and Re-P bonds in this unit. As a result, the P-Re-P angle in the photoexcited Re complex unit is changed significantly (by $5^{\circ}$ ).To confirm this, we examined the corresponding structural changesin the mononuclear complex, $\mathbf{M}^{+}$, as shown in Fig. 7 , because the photoexcitation occurs on only one Re complex unit in this case. As expected, theP-Re-Pangle in $\mathrm{M}^{+}$is decreased by $10^{\circ}$ on going from the $\mathrm{S}_{0}$ to $\mathrm{T}_{1}$ state. Because there is nochange in the distribution of the frontier molecular orbitalsin the other parts of the complex, we conclude that this bond bending is the origin of the structural changes inall the other parts.

This being the case, it is of interest to determine the driving force for the structural changes in the remainder of the complex.Upon forming the ring, the structure of $\mathrm{R} 2 \mathrm{~b}^{2+}$ becomescongested, and so the bending of the P-Re-P angle in one Re complex unitinduced by photoexcitationwould be expected to generate significant structural tensionas the result ofsteric hindrance. To reduce this tension, the structural deformation occurs inregions other than the P-Re-P angle. In particular, achange occurs in the plane consisting of the two CO ligands and Re atom of the other Re complex unit. This structural deformation mechanismexplains the unique photophysical properties of $\mathrm{R}^{2} \mathrm{~b}^{2+}$.It is known that a large structural deformation in the excited state generatesa phosphorescence red shift owing tothelarge difference in equilibrium position between the ground and excited potentials. However, this simple theory isnot applicabletoour 
case because the two complexes, $\mathbf{M}^{+}$and $\mathbf{R} 2 \mathrm{~b}^{2+}$, have quite different potentialseach other. Thus, we consider the relationship between the structural deformation and the energy of the excited state. The tensioncreated by the bending of the P-Re-P angle in one Re complex unit is presumablynot fully relaxed, because of the congested structure. In fact, the change in theP-Re-P angle in $\mathrm{R}^{2} \mathrm{~b}^{2+}$ is $5^{\circ}$, a value that is much smaller than that inM $^{+}\left(10^{\circ}\right)$. Theresidual tensionrenders the excited state somewhatunstable andthis destabilization causes the $24 \mathrm{~nm}$ phosphorescence blue shiftrelative to the mononuclear complex, even though the absorption maxima of both complexes are very similar.

This destabilization issupported by the calculations. Figure 8 summarizes the observed and calculated relative energies of the various states of both $\mathrm{R}^{2} \mathrm{~b}^{2+}$ and $\mathbf{M}^{+}$. The experimental energy values given here were estimated from the absorption and emission spectra reported in Ref. [4]. The calculated energies of the $\mathrm{S}_{1}$ states were obtained from TD-DFT calculations while those for the $\mathrm{T}_{1}$ states were derived from the optimized geometry of the lowest triplet state. Although the absolute values are different, the relative energy positions obtained from the calculations are in good agreement with the experimental data. Thisis consistent with that the specific

photophysical properties of $\mathrm{R} 2 \mathrm{~b}^{2+}$ originate from destabilization of the excited state due to residual tension.

In general, when atransition metal complex undergoes a phosphorescence blue shift, its lifetime becomes shorter because the energy gap to the triplet metal-centered state $\left({ }^{3} \mathrm{MC}\right)$, via which non-radiative decay or a ligand substitution reaction occurs. In fact, it is known thatsome Re(I) diimine tris carbonyl complexes undergo a ligand substitution reactionvia ${ }^{3} \mathrm{MC}$ [21]. In contrast, $\mathrm{Re}(\mathrm{I})$ diimine bis-carbonyl complexeshardy undergo a ligand substitutionreaction [39,40]; thus, the non-radiative decay in $\mathbf{R}^{2} \mathbf{b}^{2+}$ wouldoccurby the direct coupling to theground state. In this case, thedestabilization and structural deformationreducethe coupling to the ground stateand increasesthe quantum yield of the phosphorescenceby a factor of approximately five.These proposed mechanismson the photophysical properties do not agree with the simple theory assuming one-dimensional potentials and no change in normal modes; however, if a complex undergoes a large structural deformation so as to change the normal modes in the excited state, this assumption is no longer valid [41].

\section{Conclusion}

This study successfully acquired transient IRvibrational spectra of the ring-shaped dinuclear $\operatorname{Re}(\mathrm{I})$ diimine bis-carbonyl complex $\mathbf{R} 2 \mathbf{b}^{2+}$ in the meta-stable triplet excited state. Anomalous CO stretching vibrational bands were identified in these spectra 
compared to the spectra of mononuclear Re(I) diimine bis-carbonyl complexes. Simulated spectraof the ground $\left(\mathrm{S}_{0}\right)$ and the lowest triplet $\left(\mathrm{T}_{1}\right)$ statesobtained fromquantum chemical calculations closely matched these anomalous spectral patterns. Based on these calculations, it was determined that MLCT occurs in only one of the Re complex units and the P-Re-P angle in thisunit is significantlymodified. To reduce the tension created by this bending, the structure in other parts of the complex is deformed and this structural deformation breaks the symmetry and results in the anomalous CO stretching vibrations. Furthermore, the destabilization generated by residualtensionin the complex results in the observed phosphorescence blue shift and high quantum yield. It is expected that thissame phenomenon will also be exhibited by other ring-shaped Re(I) diimine carbonyl complexes as well as other types of ring-shaped metal complexes,andshould be helpful with regard to understanding and designing new photofunctional materials using ring-shaped compounds.

Acknowledgement

This study was supported by JST, PRESTO and JST, CREST.

References

[1] G. McDermott, S. M. Prince, A. A. Freer, A. M. Hawthornthwaite-Lawless, M. Z. Papiz, R. J. Cogdell, N. W. Isaacs, Nature, 374 (1995) 517.

[2] H. L. Anderson, J. K. M. Sanders, J. Chem. Soc., Chem. Commun., (1989), 1714.

[3] M. C. O’Sullivan, J. K. Sprafke, D. V. Kondratuk, C. Rinfray, T. D. W. Claridge, A. Saywell,M. O. Blunt, J. N. O’Shea, P. H. Beton, M. Malfois, and H. L. Anderson, Nature, 469 (2011) 72.

[4] T. Morimoto, C. Nishiura, M. Tanaka, J. Rohacova, Y. Nakagawa, Y. Funada, K. Koike, Y. Yamamoto, S. Shishido, T. Kojima, T. Saeki, T. Ozeki, O. Ishitani, J. Am. Chem. Soc. 135 (2013) 13226.

[5] T. Asatani, Y. Nakagawa, Y. Funada, S. Sawa, H. Takeda, T. Morimoto, K. Koike, O. Ishitani, Inorg. Chem. 53 (2014) 7170.

[6] J. Rohacova, A. Sekine, T. Kawano, S. Tamari, O. Ishitani, 54 (2015) 8769.

[7] L. A. Worl, R. Duesing, P. Chen, L. D. Ciana, T. J. Meyer, J. Chem. Soc. Dalton Trans. (1991) 849.

[8] D. J. Stufkens, A. Vlček, Jr. Coord. Chem. Rev. 177 (1998) 127.

[9] J. Hawecker, J.-M. Lehn, R. Ziessel, J. Chem. Soc. Chem. Commun. (1983) 536. 
[10] C. Kutal, M. A. wever, G. Ferraudi, D. Geiger, Organometallics 4 (1985) 2161.

[11] K. Kalyanasundram, J. Chem. Soc. Fraday trans. 2 (1986) 3401.

[12] H. Hori, F. P. A. Johnson, K. Koike, O. Ishitani, J. Photochem. Photobio. A 96 (1996) 171.

[13] P. Kurz, B. Probst, B. Spingler, R. Alberto, Eur. J. Inorg. Chem. (2006) 2966.

[14] H. Takeda, K. Koike, H. Inoue, O. Ishitani, J. Am. Chem. Soc. 130 (2008) 2023.

[15] A. J. Morris, G. J. Meyer, E. Fujita, Acc. Chem. Res. 42 (2009) 1983.

[16] Y. Yamazaki, H. Takeda, O. Ishitani, J. Photochem. Photobio. C: Phtotochem. Rev. 25 (2015) 106.

[17] J. M. Butler, M. W. George, J. R. Schoonofer, D. M. Dattelbaum, T. J. Meyer, Coord. Chem. Rev. 251 (2007) 492.

[18] O. Ishitani, M.W. Gerge, T. Ibusuki, F. P.A. Johnson, K. Koike, K. Nozaki, C. Pac, J.J. Turner, J.R. Westwell, Inorg. Chem. 33 (1994) 4712.

[19] I. P. Clark, M. W. George, F. P. A. Johnson, J. J. Turner, Chem. Commun. (1996) 1587.

[20] C. J. Kleverlaan, D. J. Stufkens, I. P. Clark, M. W. George, J. J. Turner, D. M. Hartino, H. van Willigen, A. Vlček, Jr., 120 (1998) 10871.

[21] K. Koike, N. Okoshi, H. Hori, K. Takeuchi, O. Ishitani, H. Tsubaki, I. P. Clark, M. W. George, F. P. A. Johnson, J. J. Turner, J. Am. Chem. Soc. 124 (2002) 11448.

[22] D.M. Dattelbaum, K.M. Omberg, J.R. Schoonover, R.L. Martin, T.J. Meyer, Inorg. Chem. 41 (2002) 6071.

[23] D. J. Liard, M. Busby, I. R. Farrell, P. Matousek, M. Towrie, A. Vlček, Jr., J. Phys. Chem. A 108 (2004) 556.

[24] L. M. Kiefer, J. T. King, K. J. Kubarych, J. Phys. Chem. A 118 (2004) 9853.

[25]A. Gabrielsson, S. Záliš, P. Matousek, M. Towrie, A. Vlček, Inorg. Chem. 43 (2004) 7380 .

[26] D.M. Dattelbaum, K.M. Omberg, P.J. Hay, N. L. Gebhart, R.L. Martin, J.R. Schoonover, T.J. Meyer, J. Phys. Chem. A 108 (2004) 3527.

[27]A. M. Blanco-Rodriguez, A. Gabrielsson, M. Motevalli, P. Matousek, M. Towrie, J. Sebera, S. Záliš, A. Vlček, Jr., J. Phys. Chem. A 109 (2005) 5016.

[28] A. Gabrielsson, P. Matousek, M. Towrie, F. Hartl, S. Záliš, A. Vlček, Jr. J. Chem. Phys. A 109 (2005) 6147.

[29] A. Gabrielsson, M. Busby, P. Matousek, M. Towrie, E. Hevia, L. Cuesta, Jr. Perez, S. Záliš, A. Vlček, Jr., Inorg. Chem. 45 (2006) 9789.

[30] S. Sato, A. Sekine, Y. Ohashi, O. Ishitani, A. M. Blanco-Rodriguez, A. Vlček, Jr., T. Unno, K. Koike, Inorg. Chem. 46 (2007) 3531. 
[31] A. El Nahhas, A. Cannizzo, F. van Mourik, A. M. Blanco-Rodriguez, S. Záliš, A. Vlček, Jr., M. Chergui, J. Phys. Chem. A 114 (2010) 6361.

[32] S. Sato, Y. Matubara, K. Koike, M. Falkenstrçm, T. Katayama, Y. Ishibashi, H. Miyasaka, S. Taniguchi, H. Chosrowjan, N. Mataga, N. Fukazawa, S. Koshihara, K. Onda, O. Ishitani, Chem. Eur. J. 18 (2012) 15722.

[33] A. Vlček, Jr., H. Kvapilová, M. Towrie, S. Záliš, Acc. Chem. Res. 48 (2015) 868.

[34] T. Mukuta, N. Fukazawa, K. Murata, A. Inagaki, M. Akita, S. Tanaka, S. Koshihara, K. Onda,Inorg. Chem.53, (2014) 2481.

[35] S. Tanaka, K. Takahashi, M. Hirata, M. Yagi, K. Onda, J. Photochem. Photobio. A: Chem. 313, (2015) 87.

[36] T. Mukuta, S. Tanaka, A. Inagaki, S. Koshihara, K. Onda, ChemistrySelect, in press.

[37]M.J. Frisch, G.W. Trucks, H.B. Schlegel, G.E. Scuseria, M.A. Robb, J.R. Cheeseman, G. Scalmani, V. Barone, B. Mennucci, G.A. Petersson, H. Nakatsuji, M. Caricato, X. Li, H.P. Hratchian, A.F. Izmaylov, J. Bloino, G. Zheng, J.L. Sonnenberg, M. Hada, M. Ehara, K. Toyota, R. Fukuda, J. Hasegawa, M. Ishida, T. Nakajima, Y. Honda, O. Kitao, H. Nakai, T. Vreven, J.A. Montgomery, Jr., J.E. Peralta, F. Ogliaro, M. Bearpark, J.J. Heyd, E. Brothers, K.N. Kudin, V.N. Staroverov, R. Kobayashi, J. Normand, K. Raghavachari, A. Rendell, J.C. Burant, S.S. Iyengar, J. Tomasi, M. Cossi, N. Rega, J.M. Millam, M. Klene, J. E. Knox, J.B. Cross, V. Bakken, C. Adamo, J. Jaramillo, R. Gomperts, R.E. Stratmann, O. Yazyev, A.J. Austin, R. Cammi, C. Pomelli, J.W. Ochterski, R.L. Martin, K. Morokuma, V.G. Zakrzewski, G.A. Voth, P. Salvador, J.J. Dannenberg, S. Dapprich, A.D. Daniels, Ö. Farkas, J. B. Foresman, J.V. Ortiz, J. Cioslowski, D.J. Fox, Gaussian 09, revision A.2.; Gaussian, Inc.: Wallingford, CT, 2009.

[38] K. Koike, J. Tanabe, S. Toyama, H. Tsubaki, K. Sakamoto, J. R. Westwell, F. P. A. Johnson, H. Hori, H. Saitoh, O. Ishitani, Inorg. Chem. 39,(2000), 2777.

[39] H. Tsubaki, A. Sekine, Y. Ohashi, K. Koike, H. Takeda, O. Ishitani, J. Am. Chem. Soc. 127 (2005) 15544.

[40] T. Morimoto, M. Ito, K. Koike, T. Kojima, T. Ozeki, O. Ishitani, Chem. Eur. J. 18 (2012) 3292.

[41] R. Englman and J. Jortner, Mol. Phys. 18 (1970) 145. 
Figure Captions

Figure 1. Molecular structures of the ring-shaped Re(I) dinuclear complex and the corresponding mono-nuclear $\operatorname{Re}(\mathrm{I})$ complex.

Figure 2. TR-IR spectraacquired $800 \mathrm{ps}$ after photoexcitation with a $400 \mathrm{~nm}$ pulsefrom acetonitrile solutions of (a) $\mathrm{R}^{2} \mathrm{~b}^{+}$and (b) $\mathbf{M}^{+}$, (c) calculated difference IR spectra between the $\mathrm{T}_{1}$ and $\mathrm{S}_{0}$ states of $\mathbf{R}_{2} \mathbf{b}^{+}$, and (d) calculated IR spectra for the $\mathrm{T}_{1}$ (red line) and $\mathrm{S}_{0}$ (blue line) states of $\mathbf{R} 2 \mathbf{b}^{+}$. The colored circles indicatethe Re(I) complex unit associated with each vibrational mode when the $\operatorname{Re}(\mathrm{I})$ complex is in the excited state (for details, see the text).

Figure 3. Vibrational phasesof CO bonds (indicated by arrows)as estimated from the calculated normal vibrational modes.The wavenumbers represent the corresponding observed and calculated vibrational bands.

Figure 4. Molecular orbitals associated with the $\mathrm{S}_{0}$ and $\mathrm{T}_{1}$ states ofR2 $\mathrm{b}^{+}$.

Figure 5. Optimized geometries of the $\mathrm{S}_{0}$ and $\mathrm{T}_{1}$ states ofR $2 \mathrm{~b}^{+}$.

Figure 6. Selected bond lengths and angles of the $\mathrm{S}_{0}$ and $\mathrm{T}_{1}$ statesofR2 $\mathrm{b}^{+}$.

Figure 7. Optimized geometries of the $\mathrm{T}_{1}$ states of $\mathbf{M}^{+}$and $\mathbf{R} 2 \mathrm{~b}^{+}$.

Figure 8.Energy diagram of the $\mathbf{S}_{0}, \mathrm{~S}_{1}$ and $\mathrm{T}_{1}$ states of $\mathbf{M}^{+}$and $\mathbf{R} 2 \mathbf{b}^{+}$. The experimental energy values were estimated from the absorption and emission maxima in Ref. [4]. 

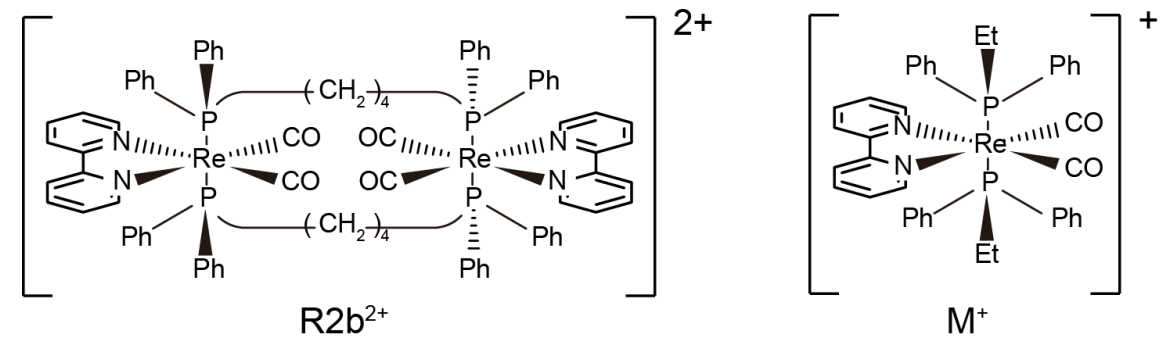

Fig. 1. S. Tanaka et al. 


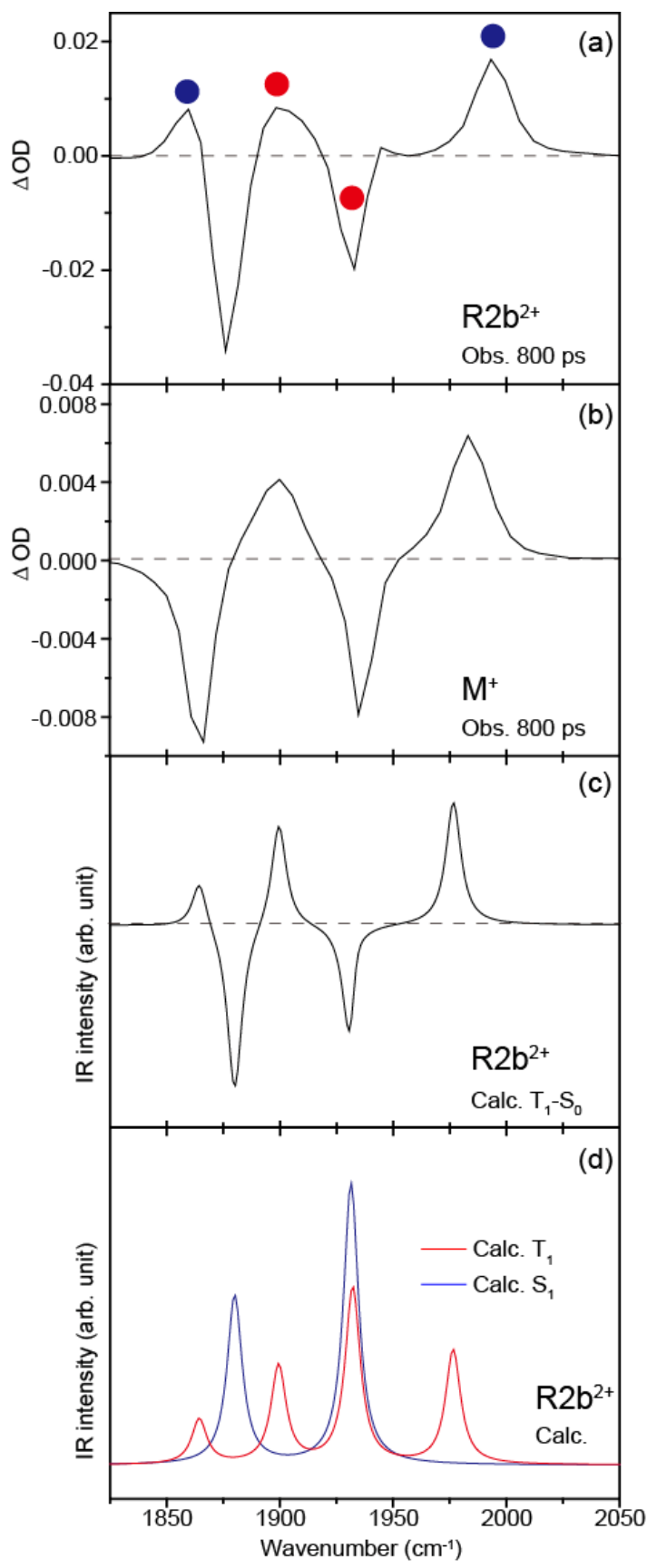

Fig. 2. S. Tanaka et al. 
Table I. Wavenumbers of the CO stretching vibrational modes in $\operatorname{Re}(\mathrm{I})(\mathrm{bpy})(\mathrm{CO})_{2} \mathrm{~L}_{2}(\mathrm{~L}=$ monodentate ligand) complexes.Here $v_{\text {GS }}$ and $v_{\mathrm{ES}}$ designate ground and excited states and $\Delta v$ is $v_{\mathrm{ES}}-v_{\mathrm{GS}}$.

\begin{tabular}{llll}
\hline Complex & $v_{\mathrm{GS}}\left(\mathrm{cm}^{-1}\right)$ & $v_{\mathrm{ES}}\left(\mathrm{cm}^{-1}\right)$ & $\Delta v\left(\mathrm{~cm}^{-1}\right)$ \\
\hline$\left[\mathrm{Re}(\mathrm{bpy})(\mathrm{CO})_{2}\left(\mathrm{Ph}_{2} \mathrm{P}-\mathrm{C}=\mathrm{C}-\mathrm{PPh}_{2}\right)_{2}\right]+(\text { in acetonitrile })^{\mathrm{a}}$ & 1870 & 1905 & +35 \\
& 1940 & 1990 & +50 \\
$\left.\left[\mathrm{Re}(\mathrm{bpy})(\mathrm{CO})_{2}\{\mathrm{P}(\mathrm{OEt}))_{3}\right\}_{2}\right]+(\text { in dichloromethane })^{\mathrm{b}}$ & 1882 & 1927 & +45 \\
& 1956 & 2012 & +56 \\
$\mathbf{M}^{+}($in acetonitrile $)$ & 1863 & 1900 & +37 \\
& 1934 & 1983 & +49 \\
$\mathrm{R}^{2} \mathrm{~b}^{2+(\text { in acetonitrile })}$ & 1876 & 1860 & -16 \\
& & 1900 & +24 \\
& 1932 & 1994 & +62 \\
\hline
\end{tabular}

aRef. [8]

bRef. [18] 


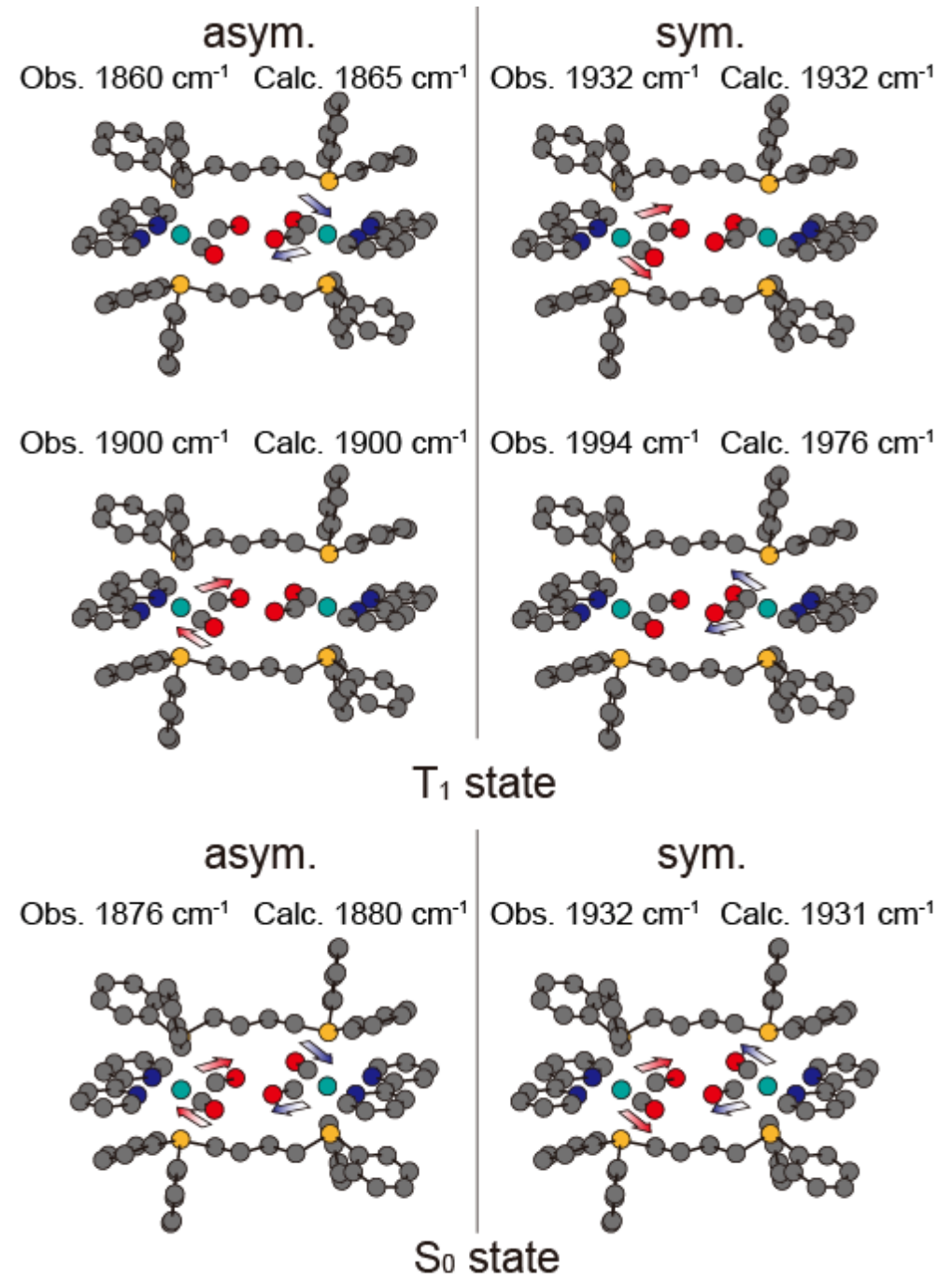

Fig. 3. S. Tanaka et al. 

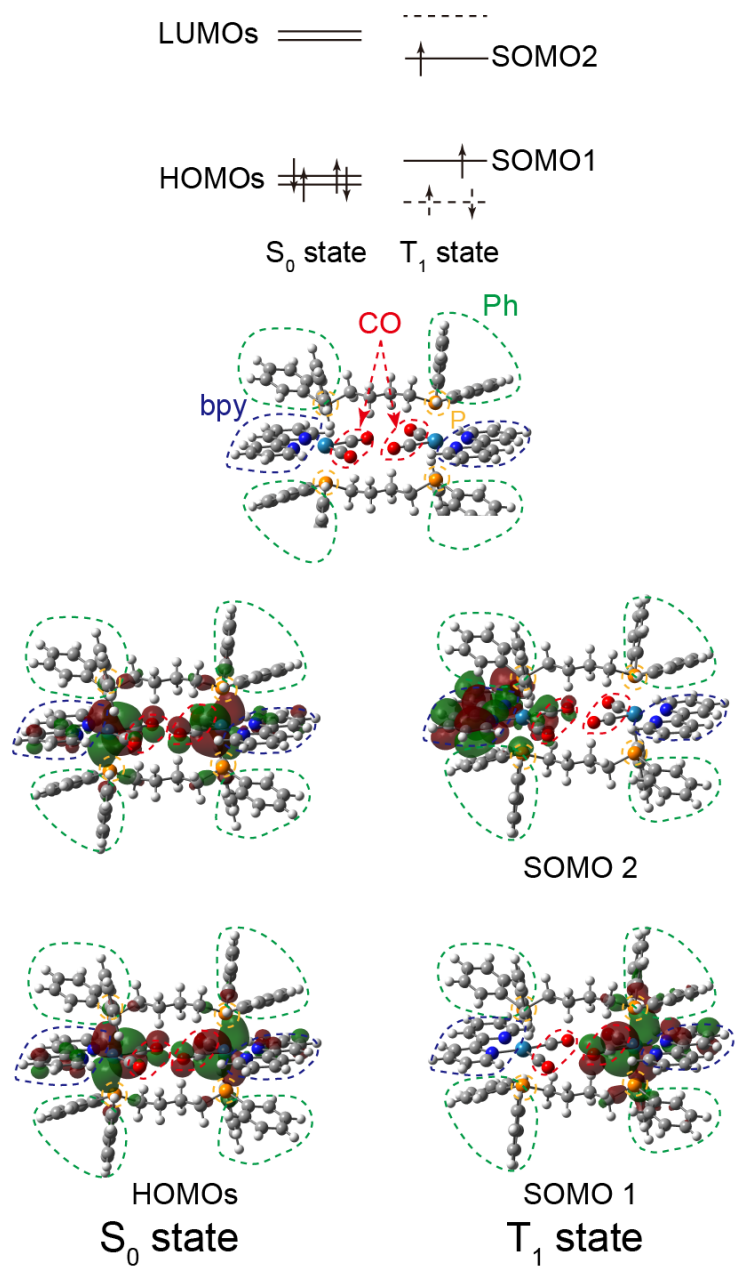

Fig. 4. S. Tanaka et al. 

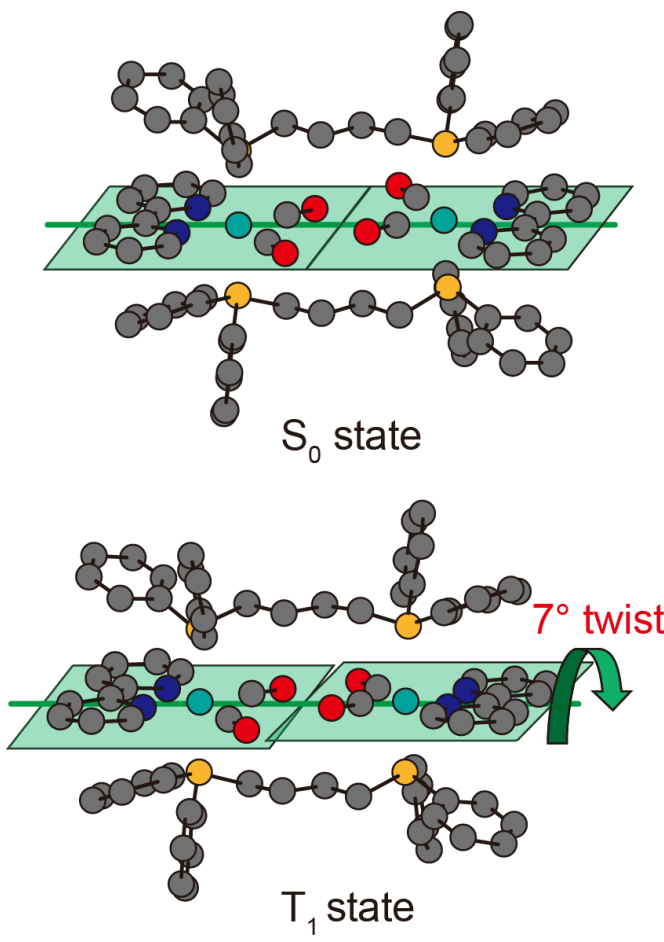

Fig. 5. S. Tanaka et al. 


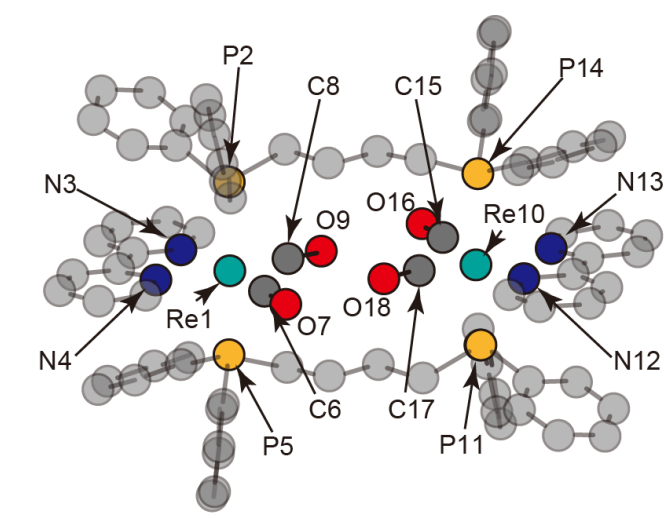

\begin{tabular}{clcc}
\hline \hline \multicolumn{2}{c}{ Structure parameter } & $\mathrm{S}_{0}$ & $\mathrm{~T}_{1}$ \\
\hline bond length & $\operatorname{Re} 1-\mathrm{P} 2$ & $2.52 \AA$ & $2.57 \AA$ \\
& $\operatorname{Re} 1-\mathrm{P} 5$ & $2.52 \AA$ & $2.57 \AA$ \\
& $\operatorname{Re} 10-\mathrm{P} 11$ & $2.52 \AA$ & $2.52 \AA$ \\
& $\operatorname{Re} 10-\mathrm{P} 14$ & $2.52 \AA$ & $2.52 \AA$ \\
& $\operatorname{Re} 1-\mathrm{C} 6$ & $1.90 \AA$ & $1.92 \AA$ \\
& $\operatorname{Re} 1-\mathrm{C} 8$ & $1.89 \AA$ & $1.94 \AA$ \\
& $\operatorname{Re} 10-\mathrm{C} 15$ & $1.90 \AA$ & $1.89 \AA$ \\
& $\operatorname{Re} 10-\mathrm{C} 17$ & $1.89 \AA$ & $1.88 \AA$ \\
& $\mathrm{C} 6-\mathrm{O} 7$ & $1.19 \AA$ & $1.18 \AA$ \\
& $\mathrm{C} 8-\mathrm{O} 9$ & $1.19 \AA$ & $1.18 \AA$ \\
& $\mathrm{C} 15-\mathrm{O} 16$ & $1.19 \AA$ & $1.19 \AA$ \\
& $\mathrm{C} 17-\mathrm{O} 18$ & $1.19 \AA$ & $1.20 \AA$ \\
& $\mathrm{P} 2-\operatorname{Re} 1-\mathrm{P} 5$ & $175^{\circ}$ & $170^{\circ}$ \\
bond angle & $\mathrm{P} 11-\operatorname{Re} 10-\mathrm{P} 14$ & $175^{\circ}$ & $176^{\circ}$ \\
& $\mathrm{C} 6-\operatorname{Re} 1-\mathrm{C} 8$ & $90^{\circ}$ & $86^{\circ}$ \\
& $\mathrm{C} 15-\operatorname{Re} 10-\mathrm{C} 17$ & $90^{\circ}$ & $91^{\circ}$ \\
dihedral angle & & & \\
$\operatorname{Re}(\mathrm{CO})_{2}$ plane- $\operatorname{Re}(\mathrm{CO})_{2}$ plane & $0.00^{\circ}$ & $7^{\circ}$ \\
\hline \hline
\end{tabular}

Fig. 6. S. Tanaka et al. 

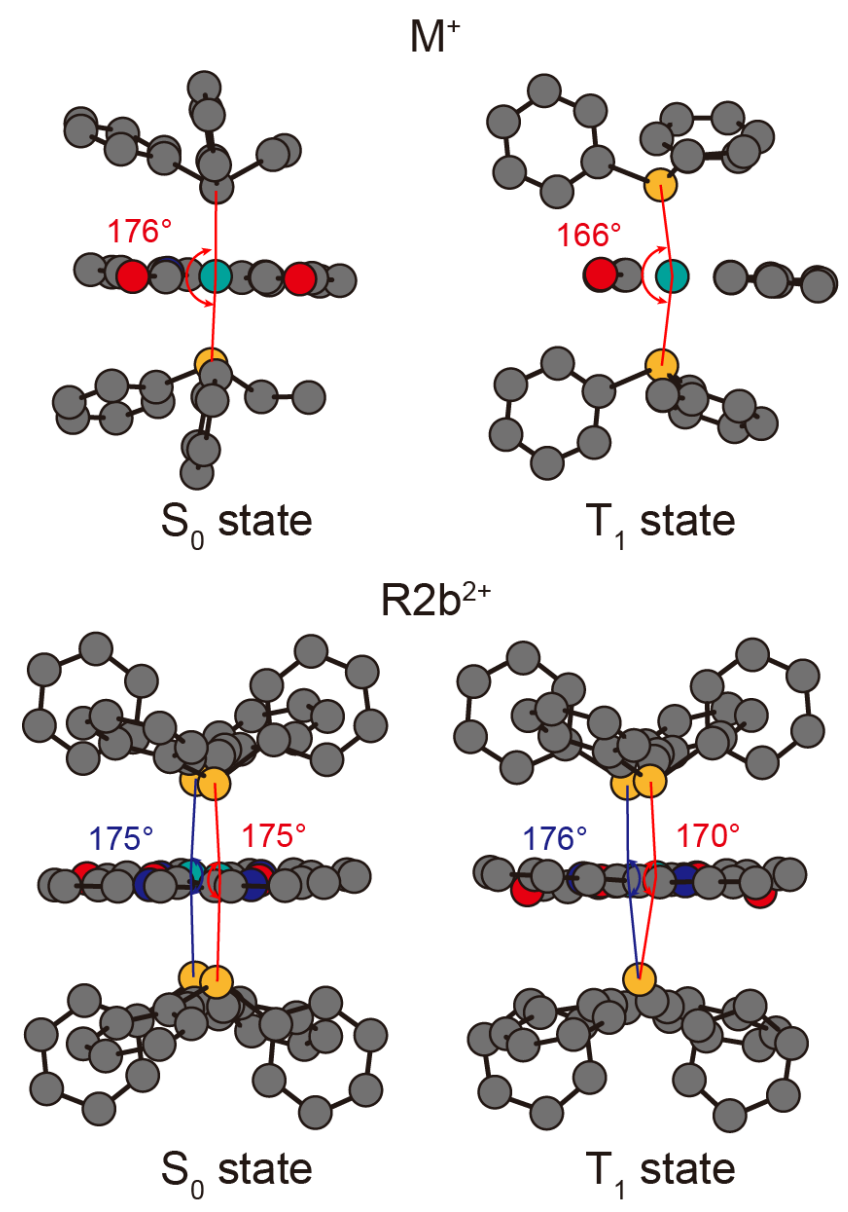

Fig. 7. S. Tanaka et al. 

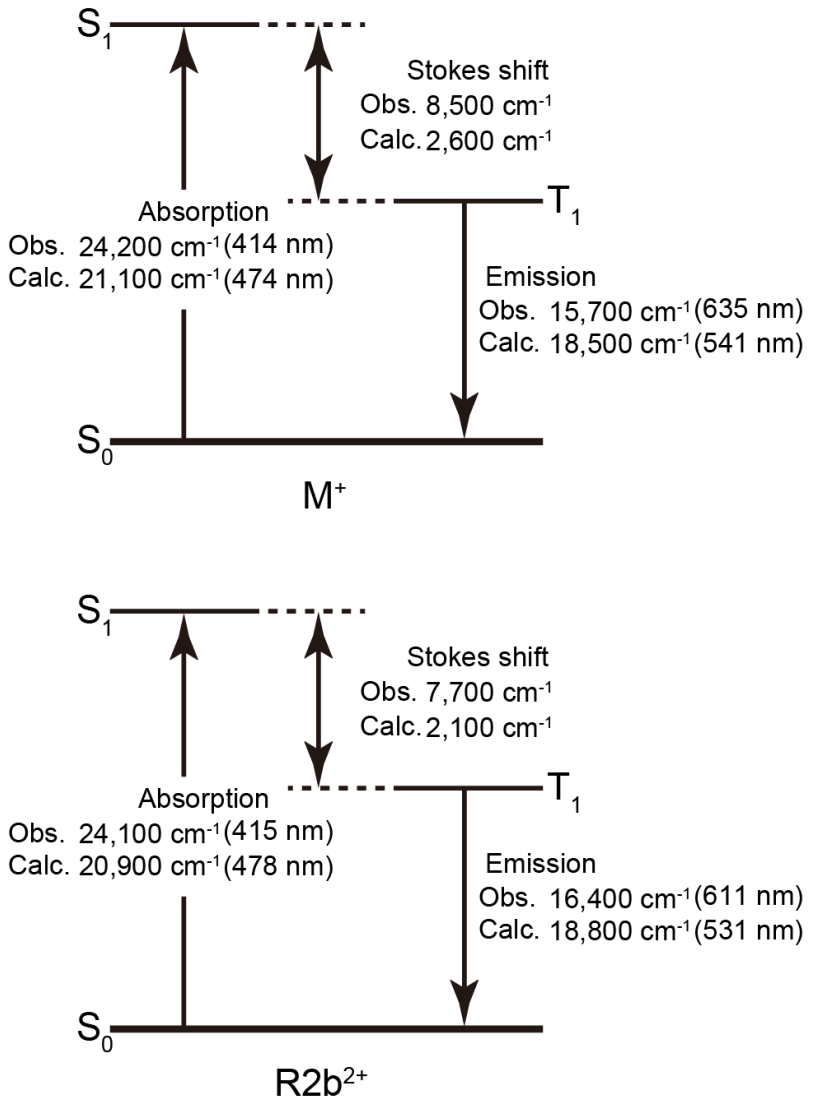

Fig. 8. S. Tanaka et al. 
Graphical Abstract
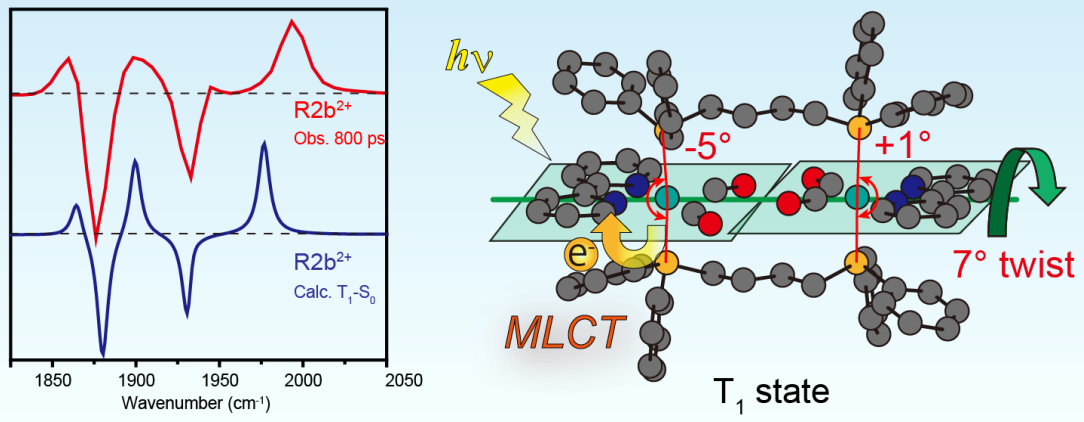